\title{
Recurrent Childhood Non-Hodgkin Lymphoma
}

National Cancer Institute

\section{Source}

National Cancer Institute. Recurrent Childhood Non-Hodgkin Lymphoma. NCI

Thesaurus. Code C115369.

The reemergence of non-Hodgkin lymphoma in childhood after a period of remission. 